\section{Screening for breast cancer}

\section{Recommendations are costly and short sighted}

EDITOR,-S Field and colleagues' recommendations for two view mammography, a shorter screening interval, double reading of films, training for staff, and a change in the density of the films are costly, short sighted proposals in human and economic terms.'

They are an attempt to address the emerging inadequacies of a programme of dubious value in terms of the primary objective, which is to reduce morbidity and mortality from breast cancer for all women. Ciaran B J Woodman and colleagues' paper highlighting the increased occurrence of interval cancers (but excluding in situ disease) $)^{2}$ coincides with Hakoma et al's report suggesting that cancers detected by screening are less aggressive and that the reduction in mortality may therefore be less than expected. ${ }^{3}$

Distributive justice demands that before more money is poured into the NHS breast screening programme we should consider the wider public health implications. ${ }^{4}$ The current cost of the programme $(£ 2 \mathrm{~m})$ is more than has been allocated $(£ 1 \cdot 2 \mathrm{~m})$ to the NHS research and development programme for new research. To cause further imbalance would be unjustifiable in the light of the main objective of reducing mortality from breast cancer.

Screening is presented as beneficial to $50-64$ year old women: such women do not understand what they are agreeing to. Altogether $17.8 \%$ of resultant diagnoses are for non-invasive cancers. In the United Kingdom ductal carcinoma in situ trial the cost is $£ 1541$ per participant per year-six times the average cost of such trials per patient $(£ 254)$ (J Houghton, meeting of British Oncological Association and British Oncology Data Managers Association, 9 November 1994). Yet three quarters of these women will not progress to an invasive cancer in their lifetime but nevertheless are labelled as having cancer and absorb costly resources. They are included in the mortality statistics but excluded from Woodman and colleagues' paper.

We should develop a total strategy for the deployment of scarce research resources to achieve the primary objective, not shore up one costly measure for detection. The NHS policy for research and development is that evidence for the effectiveness of interventions should be sought in trials: it is time we rectified this omission for population screening and that consent, with provision of balanced information, was sought from all screened women.

HAZEL THORNTON

Rowhedge,

Colchester CO5 7EA

1 Field S, Michell MJ, Wallis MGW, Wilson ARM. What should be done about interval breast cancers? BMF 1995;310:203-4. (28 January.)

2 Woodman CBJ, Threlfall AG, Boggis CRM, Prior P. Is the three year breast screening interval too long? Occurrence of interval year breast screening interval too long? Occurrence of interval
cancers in NHS breast screening programme's north western cancers in NHS breast screening program

3 Hakoma $M$, Holli J, Isola J, Kallioniemi O-P, Kärkkäinen A, Visakorpi T, et al. Aggressiveness of screen-detected breast cancers. Lancet 1995;345:221-3.

4 Thomas BA. Population breast cancer screening: theory, practice and service implications. Lancet 1995;345:205-6.

5 Advisory Group for Health Technology Assessment. Assessing the effects of health technologies. London: Department of Health Research and Development Directorate, 1992.

\section{Advice to authors}

We prefer short letters that relate to a recently published article and we are unlikely to publish letters longer than 400 words and containing over five references. Letters may be shortened. Your letters should be typed with double spacing and include a word count. All authors need to sign the letter and provide one current appointment and address. We encourage you to declare any conflict of interest. Please enclose a stamped addressed envelope if you require an acknowledgment.

\section{Incidence of interval cancer and detection} rate of first screenings are inconsistent

EDITOR,-Ciaron B J Woodman and colleagues report the first data on interval cancers from the NHS breast screening programme.' They do not comment on a serious inconsistency between the incidence of interval cancers and the detection rate at first screening, which deserves attention before conclusions are drawn from the data.

The incidences in the first three years after screening are $31 \%, 52 \%$, and $82 \%$ of the underlying incidence. This reduction in incidence after screening occurs because of the cancers that were detected by screening. In these three years the reduction is $(3 \times 100 \%)-31 \%-52 \%-82 \%=135 \%$ of the yearly incidence. The steep increase in the incidence of interval cancer back to the underlying incidence suggests that the cumulative reduction in incidence will not be much higher than $135 \%$ in following years.

The reported detection rate at first screening is $5 \cdot 9 / 1000$ screens. Thus the number of cancers detected at first screening is $322 \%$ of the underlying incidence of $1.83 / 1000$ woman years. Including ductal carcinoma in situ would reduce the ratio probably by no more than $4 \%$. Thus the number of cancers detected at screening is much higher than the decrease in cancers diagnosed clinically after screening. This inconsistency does not occur in other studies of screening for breast cancer because either the rates of interval cancer are lower or the ratio of prevalence to incidence is lower.

Assuming that no problems with registration or other errors occurred, we can think of only two explanations. Firstly, the data on incidence for the years before screening underestimate the underlying incidence. The incidence of breast cancer tends to increase with time, and the underlying incidence among screened women may be higher than that among women who refuse screening. Secondly, clinical detection of breast cancer may have shifted toward earlier stages. Though little is known about distribution by stage of breast cancers detected clinically in Britain compared with other western European countries, it is generally assumed to be or to have been less favourable. The start of the screening programme may have increased awareness in women and doctors, resulting in earlier diagnosis-outside the screening programme as well as in it. We think that the data on interval cancers do not warrant a shortening of the screening interval from three to two years unless these issues are sufficiently clarified. We have shown, however, that the marginal cost effectiveness of intensifying a good breast screening programme to intervals of two years is relatively low but that extending the upper age limit to over 65 may be more efficient. ${ }^{2}$ Statistician-informaticia HARRY J DE KONING Epidemiologist GERRIT J VAN OORTMARSSEN Mathematician

PAUL J VAN DER MAAS

Department of Public Health,

Professor of public health

Erasmus University,

PO Box 1738

3000 DR Rotterdam

Netherlands

1 Woodman CBJ, Threlfall AG, Boggis CRM, Prior P. Is the three year breast screening interval too long? Occurrence of interval year breast screening interval too long? Occurrence of interval
cancers in NHS breast screening programme's north western cancers in NHS breast screening program
region. BMF 1995;310:224-6. (28 January.)

2 De Koning HJ, van Ineveld BM, van Oortmarssen GJ, de Haes JCJM, Collette HJA, Hendriks JHCL, et al. Breast cancer screening and cost-effectiveness: policy alternatives, quality of life considerations and the possible impact of uncertain factors. Int $f$ Cancer 1991;49:531-7.

\section{Maximise compliance as well as radiological sensitivity}

EDITOR,-Ciaran B J Woodman and colleagues' paper reporting the high rate of interval cancers in the North Western Regional Health Authority ${ }^{1}$ and the accompanying editorial ${ }^{2}$ will help to increase awareness that successful breast screening has several facets. Two view mammography at the first screen is a simple and effective way of improving the yield at prevalence screens, thus reducing the potential for "false negative" interval cancers. One of the principles behind mammographic breast screening is that the earlier in the detectable preclinical phase that this (or any) modality can achieve detection the longer the delay before the rate of interval cancer approaches the underlying incidence. Unfortunately, reducing the period between screens is only a partial solution to one aspect of the problem. It can have no effect on high rates of interval cancer in the first two years after a negative screen.

Published results from the Edinburgh randomised breast screening trial provide evidence relevant to the current controversy over the British programme. Firstly, the rate of interval cancer, after four successive biennial screens, in trial women moving into the NHS programme was $9 \cdot 1$ per 10000 woman years at 23 months but had risen to 20.4 by 35 months, so that interval cancers expressed as a proportion of the control incidence increased to $67 \%{ }^{3}$ This value is intermediate between that for the two county study and that for the North Western region. Secondly, the proportional incidence of interval cancers in the first year after a negative screen fell from $28 \cdot 1 \%$ after the prevalence screen to $16.6 \%$ after the second mammographic screen and stabilised at around 5\% after later screens. ${ }^{4}$ This shows that results after the prevalence screen should not be extrapolated to subsequent screens.

Of much greater importance is the proposal mentioned in the editorial "to give radiologists additional training in the subtle mammographic signs." Optimising radiological sensitivity is an essential prerequisite for identification early in the detectable preclinical phase, thus maximising treatment of invasive cancer at the smallest size 